\title{
Online Control and Monitoring of Pressure Process Station using Yokogawa DCS
}

\author{
V.Athappan, M.Saravanabalaji
}

\begin{abstract}
In chemical process industries pressure is one of the key process variable as pressure provides a critical condition for any process in an industry. Inaccurate pressure control will result in major safety issues, poor quality, and productivity problems. More over high pressure inside a sealed vessel can cause an explosion. Therefore, it is highly desirable to keep pressure in good control and maintained within its safety limits. This paper aims for online control and monitor of pressure variable by interfacing with DCS and the same is operated as remotely triggered unit. Many process industries will monitor and control many different manufacturing processes at the same time. Overall monitoring and controlling of all the process at the same time instance will lead to increase in process productivity and plant safety. Distributed control and centralized monitoring are the key-factors to ensure the plant safety. This paper aims to enhance the flexibility in controlling and monitoring of pressure process station by configuring and developing Field Control Station (FCS) \& Human Interface Station (HIS) using DCS. The PID controller attempts to minimize the error by adjusting the controller output. The PID controller parameters are calculated by using Cohen and coon tuning algorithm. The field output of pressure process station is fetched and the parameter is been sent to the distributed control system (DCS) where the controlling and monitoring of the pressure variable in the pressure process station is performed by the DCS. Thus the optimized control of pressure process is been achieved.
\end{abstract}

\section{Index Terms: Pressure, DCS, FCS, HIS \& PID}

\section{INTRODUCTION}

Initially the plant is not connected with the DCS control panel. It is originally controlled by using the PC based control system that was set up using DAQ system, enabling users to acquire process variable, trends graph or data by having access from the pressure process station that connects with the computer along with a monitor. The control and monitoring is done directly through PC based control system. Then interfacing of the process plant along with the DCS control panel is been established with help of transmitters. In this project, the standard 4 to $20 \mathrm{~mA}$ analog transmissions are used to replace the foundation field bus, a bidirectional digital communication protocol for field devices transmitting the data is incorporated.

At Pressure process station it is been been provided a LOCAL PC based control mode and DCS control mode with the help of a toggle switch. If the toggle switch is changed to DCS

Revised Manuscript Received on July 22, 2019.

V.Athappan, Assistant Professor/Department of Electronics and Instrumentation Engineering / Kumaraguru College of Technology, Coimbatore, India.

M.Saravanabalaji, Assistant Professor/ Department of Electronics and Instrumentation Engineering / Kumaraguru College of Technology, Coimbatore, India.

mode the process station is switched to the DCS control, where the DCS panel reads the input data transmitted from Pressure process station and the FCS along with the PID control mode controls the process plant with the desired operating range. In order to operate the process plant with YOKOGAWA DCS one should switch the process station to the DCS mode. YOKOGAWA DCS is used as a control system for controlling and monitoring the pressure process plant. The control system is built based on the plant architecture. This system is enabled to control the plant $t$ by using the computer as a Human Machine interface. Input and output from the hardware is identified, in order to create a link between software and hardware equipment. This enables us to control and the hardware equipment using DCS and monitor the behavior of the process variable with respect to time.

\section{EXISTING METHOD}

Process control of large industrial plants has evolved through many stages. The PC based control system is used to control the pressure in the pressure process station where there is a process tank inside which the pressure has to be maintained at the desired operating condition. Control is been achieved with the help of process control software. In pressure process station, the control action is achieved by regulating the pressure from the compressor through a control valve. The controller will dictate the final control element where the percentage of opening of the control valve will regulate the air flow to the process tank. The accumulation of the air or pressure in the tank is sensed by pressure transmitter. The corresponding current output (4-20mA) is given to the VAD-104 data acquisition card. Every internal action is in voltage and ranges from $0-5 \mathrm{~V}$. The Personal Computer contains the built in algorithm where it acts as an error detector and controller. According to the error signal the controller will dictate the control action and the output of the controller is given to voltage to current converter where the equivalent control signal converted to $4-20 \mathrm{~mA}$ current signal is transmitted to current to pressure (I/P) converter. This signal will regulate the control valve thus enabling the process station to maintain the desired pressure inside the process tank in the pressure process station. Thus PC based control system is used to control and monitor the pressure process station. An enhancement in the control system is achieved by incorporating YOKOGAWA DCS as the online process control and monitoring system.

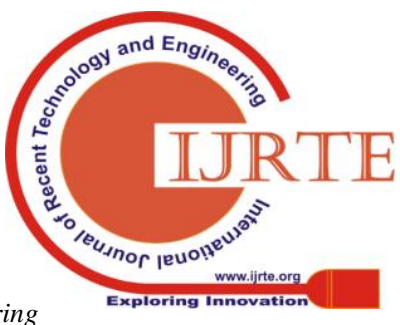




\section{Online Control and Monitoring of Pressure Process Station using Yokogawa DCS}

\section{PROCESS DESCRIPTION}

\section{A. Pressure Process Station Mainframe}

The mainframe is a metallic structure mounted on open platform. It consists of a bottom plate houses the process tanks. A frame contains pressure transmitter, I/P convertor, control valve, process tank and a cabinet. The cabinet accommodates the multi-output DC power supply and inlet socket for AC mains.

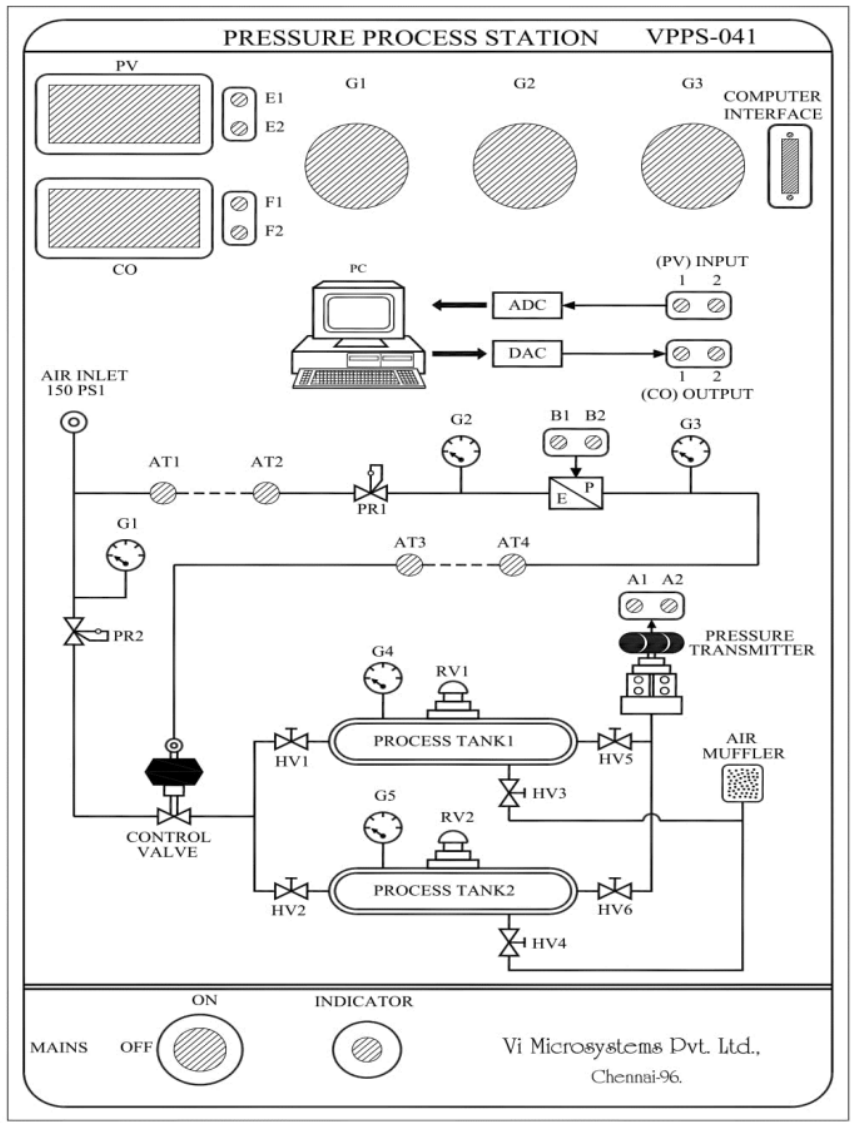

Fig 1: Front panel of Pressure Process Station

Table 1: Pressure process station main frame

\begin{tabular}{|c|c|}
\hline Mains & To switch ON/OFF the unit. \\
\hline Indicator & To indicate the power ON. \\
\hline G1 & $\begin{array}{l}\text { To indicate the input pressure from the } \\
\text { compressor. }\end{array}$ \\
\hline G2 & To indicate the output regulated pressure. \\
\hline G3 & $\begin{array}{l}\text { To indicate the output pressure of } \mathrm{I} / \mathrm{P} \\
\text { converter. }\end{array}$ \\
\hline B1, B2 & $\begin{array}{l}\text { Input (4-20) } \mathrm{mA} \text { terminals of } \mathrm{I} / \mathrm{P} \text { converter } \\
\text { output. }\end{array}$ \\
\hline E1, E2 & (4 to 20$) \mathrm{mA}$ current input in PV DPM. \\
\hline $\mathrm{F} 1, \mathrm{~F} 2$ & (4 to 20 ) $\mathrm{mA}$ current input in CO DPM. \\
\hline $\begin{array}{l}\text { (CO) } \\
\text { Output }\end{array}$ & (4 to 20 ) $\mathrm{mA}$ current output from DAC. \\
\hline HV1 & Provided for supply disturbance study \\
\hline HV2 & $\begin{array}{l}\text { Process tank output valve provided for load } \\
\text { disturbance study. }\end{array}$ \\
\hline $\begin{array}{l}\text { AT1 \& } \\
\text { AT2 }\end{array}$ & Compressor pressure measuring terminal. \\
\hline AT3 & $\begin{array}{l}\text { Pneumatic control valve input pressure } \\
\text { terminal. }\end{array}$ \\
\hline
\end{tabular}

\begin{tabular}{|l|l|}
\hline AT4 & I/P converter output pressure terminal. \\
\hline A1 & $\begin{array}{l}\text { Pressure transmitter 24V power supply } \\
\text { terminal. }\end{array}$ \\
\hline A2 & $\begin{array}{l}\text { Pressure transmitter (4-20) mA output } \\
\text { terminal. }\end{array}$ \\
\hline $\begin{array}{l}\text { (PV) } \\
\text { input } 1\end{array}$ & In built +24V positive terminal. \\
\hline $\begin{array}{l}\text { (PV) } \\
\text { input 2 }\end{array}$ & Channel 1 ADC input terminal. \\
\hline $\begin{array}{l}\text { Computer } \\
\text { Interface }\end{array}$ & $\begin{array}{l}\text { Provision to interface the process station with } \\
\text { computer through the cable. }\end{array}$ \\
\hline
\end{tabular}

\section{B. Technical Specifications}

The following table will give a detailed description about the technical specifications of the pressure process tank.

Table 2: Technical Specifications

\begin{tabular}{|c|c|}
\hline \multicolumn{2}{|l|}{ PROCESS TANK } \\
\hline Material Make & Mild steel with powder coated \\
\hline Length & $400 \mathrm{~mm}$ \\
\hline Height & $250 \mathrm{~mm}$ \\
\hline Thickness & $4 \mathrm{~mm}$ \\
\hline Working pressure & 150 PSI \\
\hline \multicolumn{2}{|c|}{ PNEUMATIC CONTROL VALVE } \\
\hline Make & RK Valve \\
\hline Type & Single seated globe \\
\hline Trim Mat. & SS-316 \\
\hline Characteristics & Equal \% \\
\hline Body Mat & CS Body \\
\hline Spring Range & $(0.2-1) \mathrm{Kg} / \mathrm{cm}$ \\
\hline Medium & Water / Air. \\
\hline Valve Action & Air to open. \\
\hline End Connection & 3/4" Flanged. \\
\hline \multicolumn{2}{|c|}{ PRESSURE REGULATOR } \\
\hline Make & PLACKA Instruments \& Control \\
\hline $\begin{array}{l}\text { Maximum input } \\
\text { pressure }\end{array}$ & $8 \mathrm{~kg} / \mathrm{cm} 2$ \\
\hline Output pressure & $(0$ to 2.1$) \mathrm{Kg} / \mathrm{cm} 2$ \\
\hline Special Features & Regulator/Filter. \\
\hline \multicolumn{2}{|c|}{ ELECTRO PNEUMATIC CONVERTOR } \\
\hline Make & Watson Smith \\
\hline Input Air & 20 Psi constant pressure \\
\hline Signal input & (4 to 20$) \mathrm{mA} \mathrm{DC}$ \\
\hline Output & Pneumatic signal (3 to 15 ) PSI \\
\hline End connection & 1/4" BSP [F] Thread \\
\hline \multicolumn{2}{|c|}{ MULTI OUTPUT DC POWER SUPPLY } \\
\hline Input & $230 \mathrm{VAC} / 50 \mathrm{~Hz}$ \\
\hline Output & $+24 \mathrm{~V} \mathrm{DC}: 750 \mathrm{~mA}$ \\
\hline \multicolumn{2}{|c|}{ DIGITAL PANEL METER } \\
\hline Make & MECO/ Nippon \\
\hline Range & $(0-200) \mathrm{mA}$ \\
\hline Supply & $230 \mathrm{~V} \mathrm{AC} / 50 \mathrm{~Hz}$ \\
\hline Size & $(92 \times 46) \mathrm{mm}$ \\
\hline \multicolumn{2}{|c|}{ PRESSURE TRANSMITTER } \\
\hline Make & ABB / Rosemount \\
\hline
\end{tabular}




\begin{tabular}{|l|l|}
\hline Type & 2 Wire \\
\hline Range & 7bar \\
\hline Supply & 24V DC \\
\hline Output & $(4-20) \mathrm{mA}$ \\
\hline PRESSURE GAUGE & \multicolumn{2}{|l|}{} \\
\hline Make & Waaree / Manometer \\
\hline Body material & SS \\
\hline Size & $2.5^{\prime \prime}$ \\
\hline Mounting & Panel \\
\hline End connection & $1 / 4 "$ BSP Back connection \\
\hline
\end{tabular}

\section{PROPOSED METHOD}

Pressure is the important physical variable of the industrial process and it is taken in account for online control and monitor using YOKOGAWA DCS. Controlled variable is pressure inside the chamber. It is the one that must be maintained precisely at the set point. Manipulated variable is inflow rate of the pressure inside the closed chamber. Thus flow rate of compressed air from the air compressor has to be regulated in order to maintain the controlled variable equal to the set point value. The load variable may change either continuously or sporadically with some function of time. The load variables are independent variables. When there is a change in these variables, it will upset the control system and their effects can only be corrected in a feedback manner. The accumulation of the air in the tank is known as a pressure of the tank, which is sensed by pressure transmitter. The DCS sends the set point required by the process to the controller which instructs a control valve to operate so that the process reaches and stays at the desired set point. Network reliability is increased by dual redundancy cabling over diverse routes. This distributed topology also reduces the amount of field cabling by setting the I/O modules and their associated processors close to the process plant.

\section{A. Process Description}

The pressure in the process tank is measured using the pressure transmitter. Pressure transmitter senses the process variable (pressure signal) and converts it into 4-20mA current signal. The current output from the pressure transmitter which is of range (4-20) $\mathrm{mA}$ is passed into the input slot of DCS. Controller compares the actual pressure with the desired pressure and generates an error signal. Then this deviation is supplied to the main PID controller. The controller in turn changes the value of the manipulated variable (flow rate of pressure) in such a way to reduce the magnitude of the deviation through the final control element.

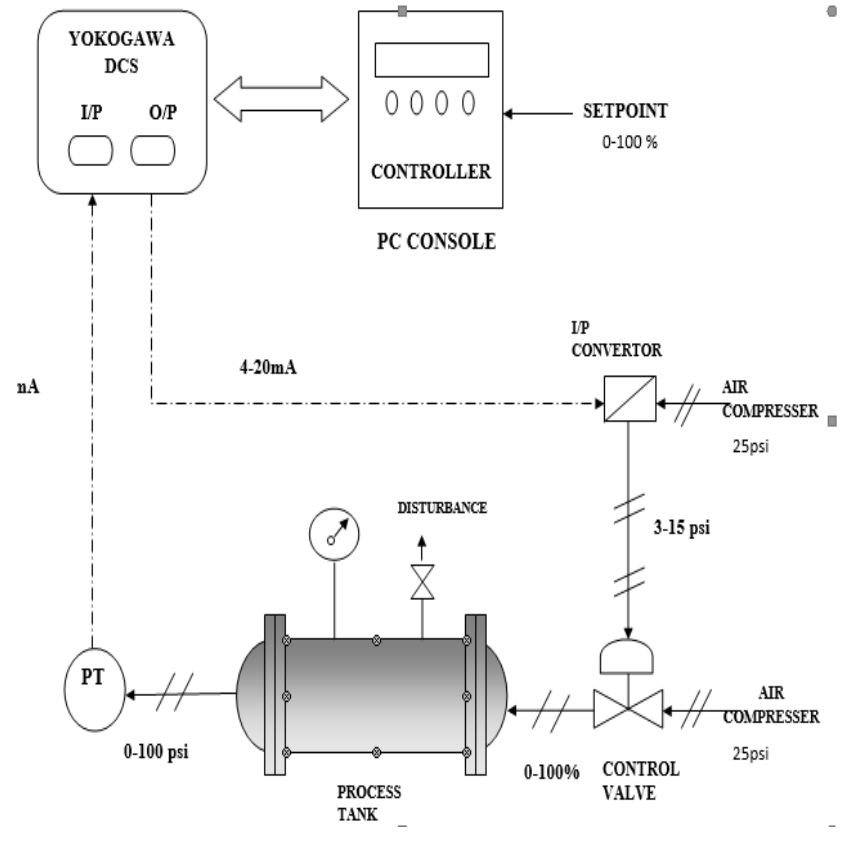

Fig 2: Process Flow Diagram

Initially, the current signal which is of range (4-20) $\mathrm{mA}$ is converted into a pressure signal of (3-15) PSI using a current to pressure converter. This pressure signal is used to activate the control valve to open between 0-100 percent according to the controller output to maintain the process tank at desired set point pressure.

The air supply to the current to pressure (I/P) converter and the control valve is provided by the air regulator. Air supply to air regulator is provided by the air compressor. The air compressor provides a pressure signal of $25 \mathrm{psi}$ and $75 \mathrm{psi}$ respectively to the two air regulators. Once the compressor is turned on, the pressure signal is provided to the air regulator.

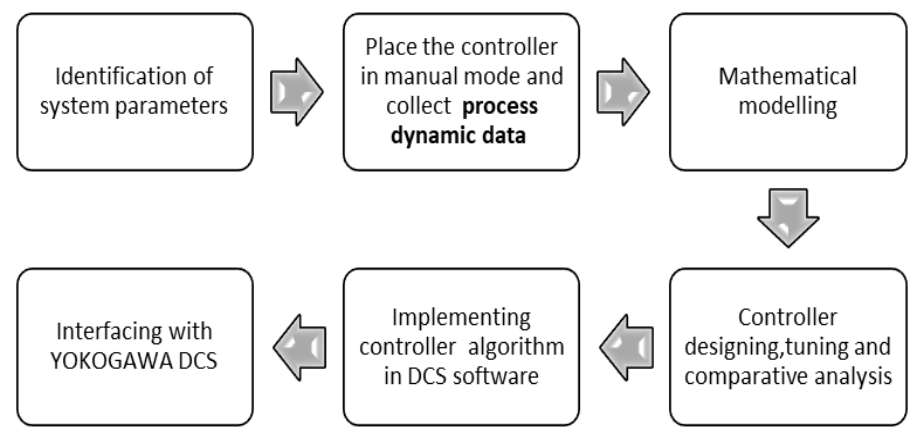

Fig 3: Process Flow chart

\section{B. Mathematical Modelling}

Mathematical modeling of any control system is the first and foremost task that a control engineer has to accomplish for design and analysis of any control engineering problem. It is nothing but the process or technique to express the system by a set of mathematical equations (algebraic or differential in nature).

Different mathematical models: Commonly used mathematical models are-

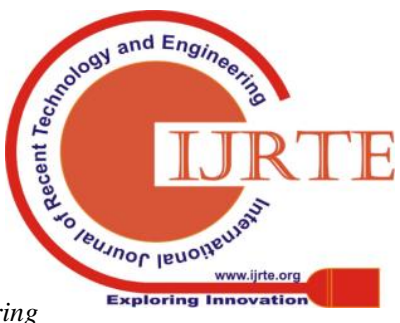




\section{Online Control and Monitoring of Pressure Process Station using Yokogawa DCS}

1. Differential equation model.

2. State space model.

3. Transfer function model.

Here we use transfer function model for our process system.

Transfer function model:

It is the ratio of Laplace transform of output to Laplace transform of input.

Theoretical Method:

Consider a pressure tank

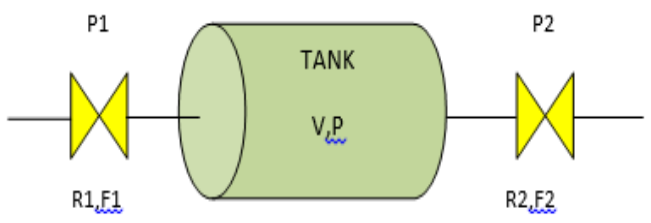

Fig 4: Pressure tank

Temperature is assumed constant.

$$
w i=\frac{d(1 p)}{d t}
$$

Where

$$
\begin{aligned}
& \text { V-volume of the tank } \\
& \text { P-varying pre } \\
& \text { P1-inlet pressure } \\
& \text { F1-inlet flow } \\
& \text { R1-resistance at inlet side } \\
& \text { P2-outlet pressure } \\
& \text { F2-outlet flow } \\
& \text { R2-resistance at outlet side }
\end{aligned}
$$

Accumulation in the tank=input flow rate (F1)-output flow rate $(\mathrm{F} 2)$

$$
\begin{gathered}
\frac{V d P}{d t}=\frac{P 1-P}{R 1}-\frac{(P-P 2)}{R 2} \\
\frac{V d P}{d t}+\frac{P(R 1+R 2)}{R 1 R 2}=\frac{P 1}{R 1}+\frac{P 2}{R 2}
\end{gathered}
$$

\section{RIR2}

Multiply by $\overline{R 1+R 2}$ on both sides,

$$
\begin{gathered}
V\left(\frac{R 1 R 2}{R 1+R 2}\right)\left(\frac{d P}{d t}\right)+P=\frac{R 1 R 2}{R 1+R 2}\left(\frac{P 1}{R 1}\right)+\frac{R 1 R 2}{R 1+R 2}\left(\frac{P 2}{R 2}\right) \\
\tau_{p}\left(\frac{d P}{d t}\right)+P=K_{1} P_{1}+K_{2} P_{2} \\
K_{1}=\frac{R 2}{R 1+R 2} \quad K_{2}=\frac{R 1}{R 1+R 2} \quad \tau_{p}=\frac{V R 1 R 2}{R 1+R 2}
\end{gathered}
$$

Taking Laplace transform,

$$
\tau_{p} s P(s)+P(s)=K_{1} P_{1}(s)+K_{2} P_{2}(s)
$$

$$
P(s)=\frac{K_{1} P_{1}(s)}{\tau_{p} s+1}+\frac{K_{2} P_{2}(s)}{\tau_{p} s+1}
$$

\section{PRACTICAL APPROACH}

\section{Cohen Coon tuning method:}

The Cohen-Coon tuning rules are suitable for use on self-regulating processes if the control objective is having a fast response. Thus this method is employed for tuning the controller parameters of the PID controller.

\section{TUNING PROCEDURE}

Assuming the control loop is linear and the final control element is in good working order, we can continue with tuning the controller. The Cohen-Coon tuning rules use three process characteristics: process gain, dead time, and time constant. These are determined by doing a step test and analyzing the results.

\section{Step Test for Tuning:}

1. Place the controller in manual and wait for the process to settle down.

2. Make a step change of a few percent in the controller output $(\mathrm{CO})$ and wait for the process variable (PV) to settle out at a new value. The size of this step should be large enough that the process variable moves well clear of the process noise/disturbance level. A total movement of five times the noise/disturbances on the process variable should be sufficient.
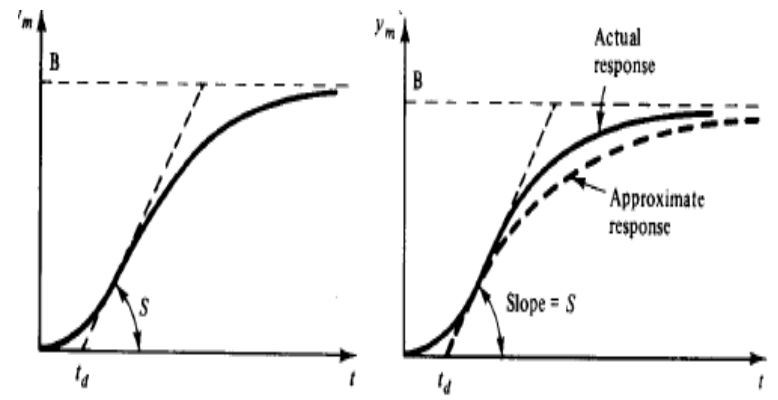

Fig 5.Cohen coon Controller tuning

3. Convert the total change obtained in PV to a percentage of the span of the measuring device.

4. Calculate the process gain (k) as follows:

$$
\mathrm{k}=\text { change in PV [in \%] / change in CO [in \%] }
$$

5. Find the maximum slope on the PV response curve. This will be at the inflection point (where the PV stops curving upward and begins curving downward). Draw a line tangential to the PV response curve through

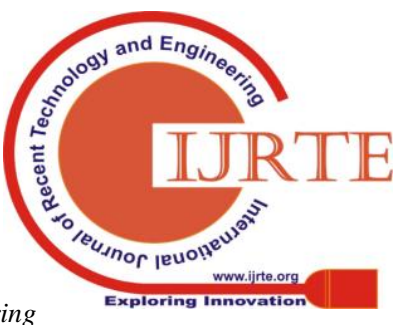

Pues Intelligence Engineering \& Sciences Publication 
the point of inflection. Extend this line to intersect with the original level of the PV (before the step change in $\mathrm{CO})$. Take note of the time value at this intersection.

6. Measure the dead time (td) as follows:

$\mathrm{td}=$ time difference between the change in $\mathrm{CO}$ and the intersection of the tangential line and the original PV level.

7. Calculate the value of the PV at $63 \%$ of its total change. On the PV reaction curve, find the time value at which the PV reaches this level.

8. Measure the time constant (Greek symbol tau) as follows:

$\tau=$ time difference between intersection at the end of dead time, and the PV reaching $63 \%$ of its total change.

9. Convert your measurements of dead time and time constant to the same time-units your controller's integral mode uses. E.g. if your controller's integral time is in minutes, use minutes for this measurement.

10. Do two or three more step tests and calculate the process gain, dead time, and time constant for each test to obtain a good average of the process characteristics. If we get vast different numbers every time, we must repeat the procedure even more until we have a few step tests that produce similar values. Use the average of those values.

11. Calculate new tuning settings using the Cohen-Coon tuning rules below. Note that these rules produce a quarter-amplitude damping response. See the next step.

12. Divide the calculated controller gain by two to reduce oscillations and improve loop stability.

13. Compare the newly calculated controller settings with the ones in the controller, and ensure that any large differences in numbers are expected and justifiable.

14. Make note of the previous controller settings, the new settings, and the date and time of change.

15. Implement and test the new controller settings. Ensure the response is in line with the overall control objective of the loop.

16. Leave the previous controller settings with the operator in case he/she wants to revert back to them and cannot find you to do it. If the new settings don't work, you have probably missed something in one or more of the previous steps.

17. Monitor the controller's performance periodically for a few days after tuning to verify improved operation under different process conditions.

Table 3. Controller Parameters

\begin{tabular}{|l|l|l|l|}
\hline Controller Mode & Kp & Ti & Td \\
\hline
\end{tabular}

\begin{tabular}{|c|c|c|c|}
\hline $\mathrm{P}$ & 6.48 & - & - \\
\hline $\mathrm{PI}$ & 5.61 & 52.138 & - \\
\hline PID & 8.443 & 48.69 & 7.468 \\
\hline
\end{tabular}

\section{INTERFACING DCS WITH PROCESS STATION}

\section{A. CREATING A PROJECT}

A Project in CENTUM VP is created under the system view. In the system view new project has been created with our project name.

STEP 1: create an outline of new project

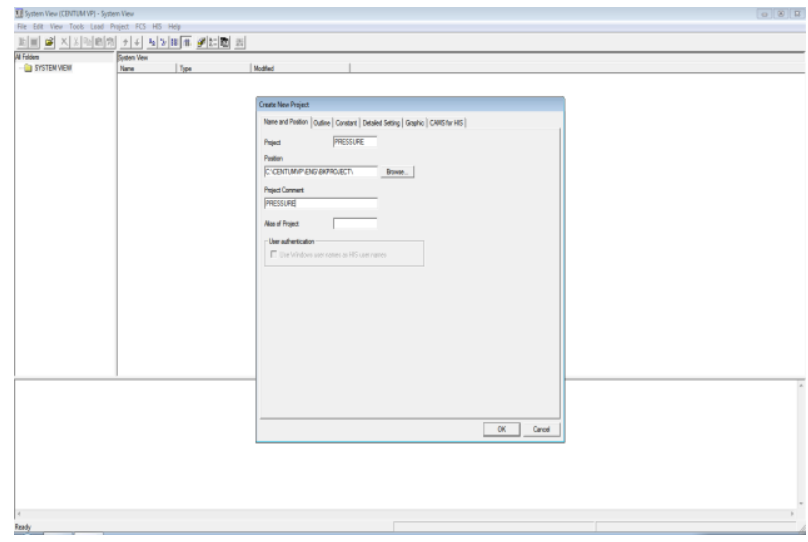

Fig 6: Outline of the project

STEP 2: For the new project field control station (FCS) which acts as an interface between field instruments and control room has been created.

STEP 3: The NODE units are SIGNAL PROCESSING UNITS which converts and transmits I/O signals from FIELD DEVICES to FIELD CONTROL UNIT where the processor does operation.

STEP 4: Analog I/O card configuration:

- First create IOM and define its builder

- To configure individual channels of IOM created. Double click on the I/O card to go to IOM builder.

- Creation of analog I/P block and name the I/P as $\% \%$ PT01

\section{a.Control Drawing Builder}

It is used to configure the basic control functions of the FCS. To access it, select the FUNCTION BLOCK folder from FCS folder. After all I/O have been assigned to system, function diagram is built.

PVI [PROCESS VARIABLE INDICATOR] Block:

This function block displays an input signal from the I/O modules or from the other blocks as process variable (PV). It can also output the process variable (PV) from the OUT terminal.

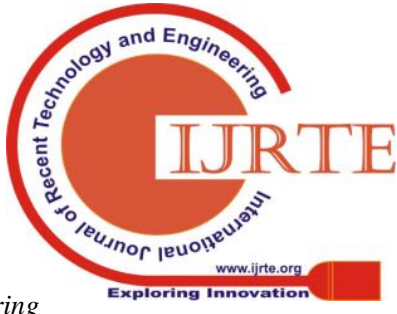




\section{Online Control and Monitoring of Pressure Process Station using Yokogawa DCS}

PID Controller Block:

The PID controller block (PID) provides the most general control function to perform proportional-integral-derivative control based on the deviation of the process variable (PV) from the set point value (SV). To set the properties of the PID block select the block, right click and select the option of edit detail of PID controller block.

\section{HIS CREATION}

1. For the new project human interface station (HIS) from which the operator controls the plant also used for configuration has been created.

2. The graphic field controller is designed and finally project is downloaded.

3. Process diagram can be drawn using the available stencils and Pressure flow can be observed.

Finally pressure process station is interfaced with the YOKOGAWA DCS station and process is controlled and monitored using PC Console.

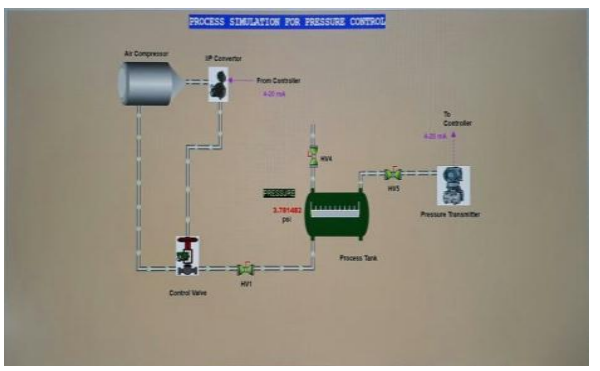

Fig 7: Graphical View HIS display

\section{RESULT}

Controller tuning allows for optimization of a process and minimize the error between the variable of the process and its set point value. In the YOKOGAWA system $\mathrm{P}$, I, D values are used to control the pressure level. In the industry, normally the output should be calculated faster so that the operator can perform action faster. The PID controller attempts to minimize the error by adjusting the controller output. The PID gain values are calculated by using Cohen and Coon tuning algorithm. Set point is assigned as 30\% (30psi) and tuned P, I, $\mathrm{D}$ values are substituted.

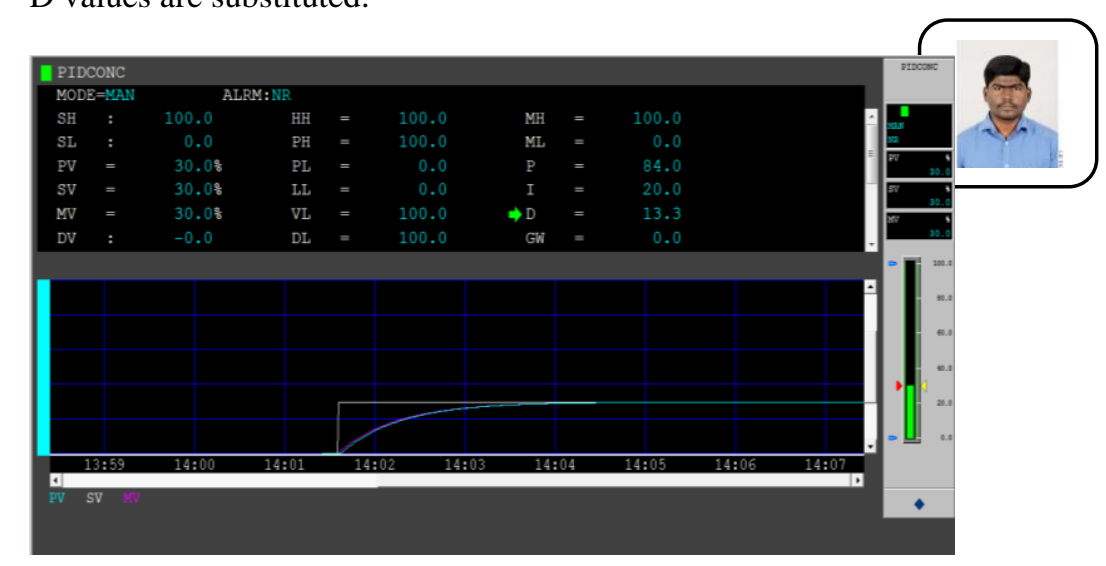

Fig 8: Tuning window

\section{CONCLUSION}

Pressure is the real time variable that has many impacts on industrial process which is considered in this project and it is controlled perfectly with the help of PID controller using YOKOGAWA DCS. By connecting the process plant station to DCS, it has been proven that better control is achieved when compared with PC based control system. DCS gives the industrial platform of controlling and monitoring the pressure process plant using high level human machine interface. Thus an optimum control and monitoring of any real time variable is highly achieved using Distributed control system.

\section{REFERENCES}

1. D.Angeline Vijula, V.Thangapandi, K.Vasanth Kumar, B.Vignesh "Controlling and Monitoring of Industrial Pressure Process using Distributed Control System", INTERNATIONAL JOURNAL OF INNOVATIVE RESEARCH IN ELECTRICAL, ELECTRONICS, INSTRUMENTATION AND CONTROL ENGINEERING, Vol. 3 , Issue 2, February 2015.

2. Design field controller for level, flow, temperature and networking using YOKOGAWA DCS. 5th International Conference on Mechatronics (ICOM'13). IOP Conf. Series: Materials Science and Engineering 53 (2013) 012094

3. GyanRanjanBiswal, Maheshwari R.P., Dewal M.L. (2012)'Modeling, Control and Monitoring of Hydrogen Cooling System in Thermal power plant'IEEE Transactions on Industrial Electronics. Vol.59,No.1,pp.562-569.

4. Brendan Galloway, Gerhard Hancke,P. (2008) 'Introduction to Industrial Control Networks',IEEE Transactions on Instrumentation and Measurements Vol.56, No.1, pp.5-10

5. Francesco Adamo, Filippo Attivissiono, Giuseppe Cavone, Nicola Giaquinto (2007), 'SCADA/HMI system in Advance Educational Courses',IEEE Transactions on Instrumentation and Measurements Vol.56,No.1,pp.4-9.

6. George Stephanopoulos,S. (1984) 'Chemical process control ', Prentice - Hall publication, New Jersey, Eastern Economy Edition.

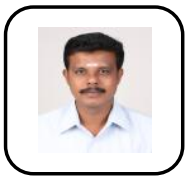

\section{AUTHORS PROFILE}

V.Athappan, graduated from Annamalai University in 1998 with a bachelor's degree in Electronics and Instrumentation Engineering. Also obtained the University First Rank during M.Tech Program in Control and Instrumentation from Thiagarajar College of Engineering, Madurai. Pursuing Ph.D. in NIT,

Trichirapalli. Has published paper in the areas of Process Control and Controller Design.

M.Saravanabalaji graduated from Anna University, Coimbatore has a master's degree in Control and Instrumentation. Pursuing Ph.D. in NIT, Trichirapalli. Has published papers in the areas of Process Control, Controller Design and Flow Line Leak Detection System. 